\title{
استخدام المناطق الصناعية الايكولوجية فى تخفيض تكاليف الطاقة الشمسية الحرارية Using Eco- industrial Park in reducing The costs of Concentrating Solar Power
}

\author{
محمود سيد على الصادق
}

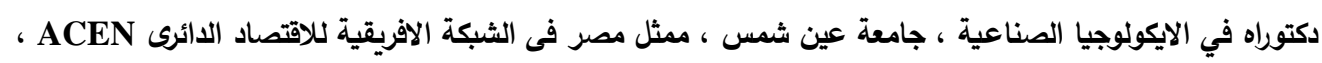

خبير معتمد فى ادارة الطاقة PA-CEMP ، خبير معتمد فى اقتصاديات البيئة والمحاسبة البيئية ،

mahmoud_sayed101074@yahoo.com

ملخص البحث:

يهذف هذا البحث إلى تقليل تكاليف الاستثمار فى الطاقة الثمسية الحرارية من خلال التركيز على التطبيقات الصناعية مثل استخدام البخار والحرارة والكهرباء بالاعتماد على منطقة صناعية ايكولوجية تقوم على مبادئ وأساليب علم الايكولوجيا

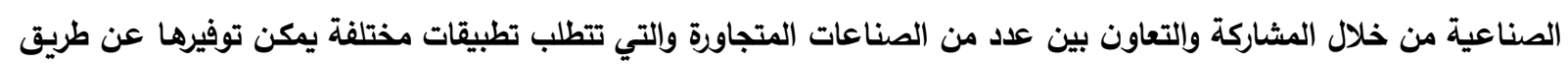
محطة الطاقة الثمسية الحرارية. فمن خلال اكتثاف العلاقات التكافلية لمجموعة من الصناعات المتجاورة يمكن تحقيق وفورات في تكاليف الإنتاج وفوائد جماعية تمكن من التغلب على المعوقات الفنية والمالية التي تواجه الثركات الفردية عند الاستثمار فى الطاقة الثمسية الحرارية.

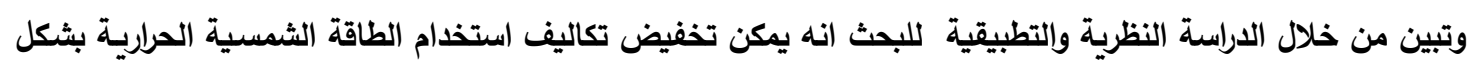

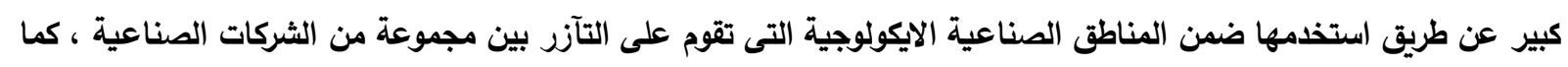

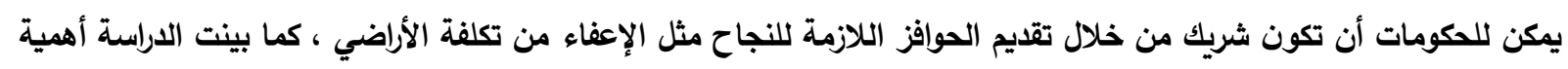

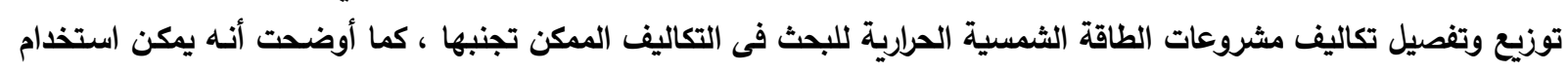

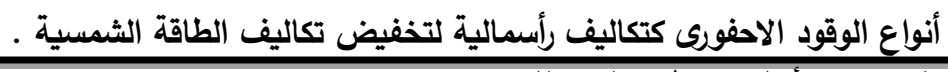

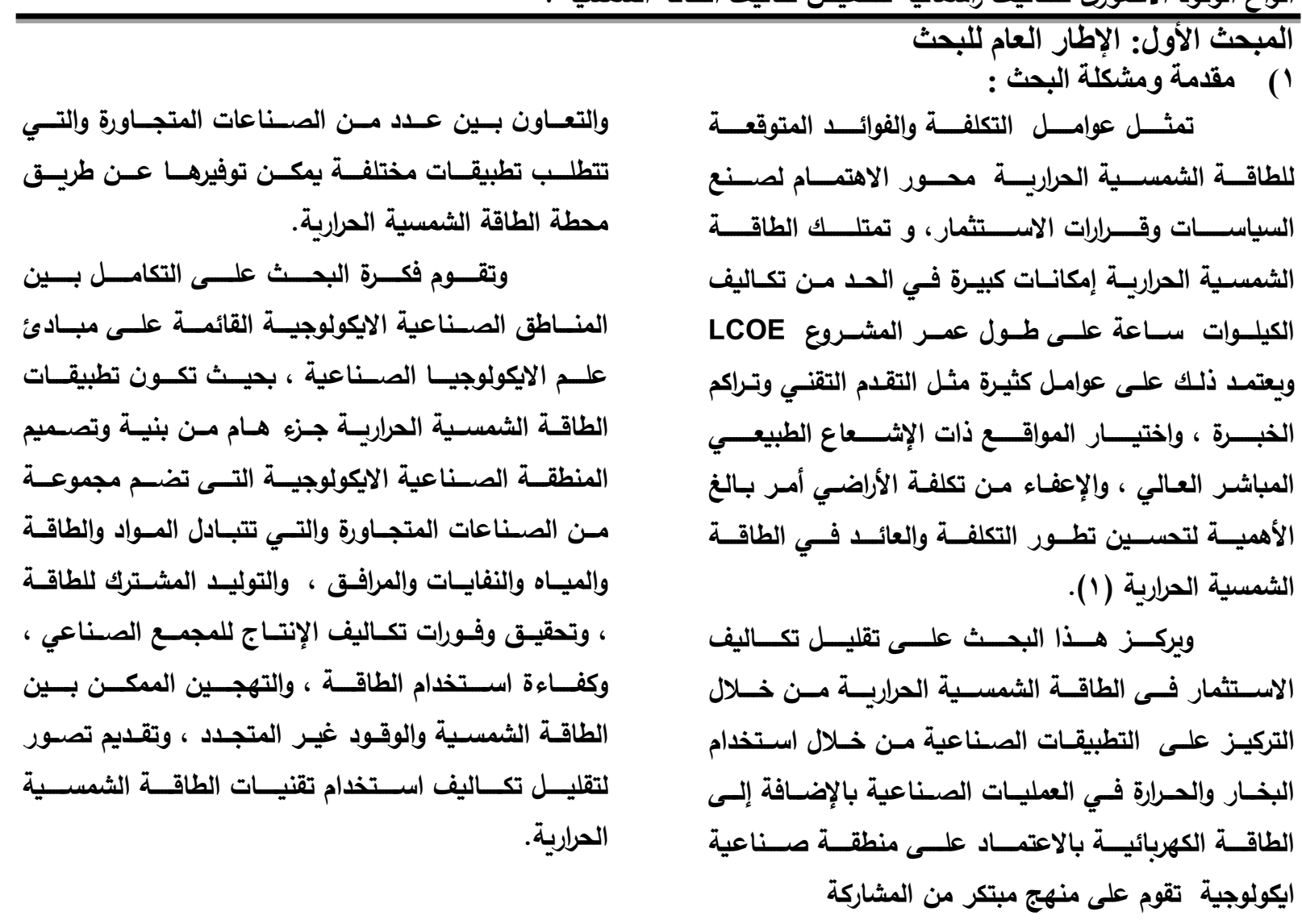


ســاهمت هـذه الدراســة فـي إعـــاد دليـل لتصــيم

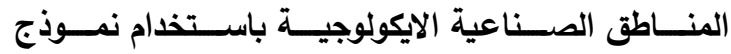
محاكساة شـبكة غذائيسة في النظــام الايكولـوجي الطبيعسي ، وقدم النموذج ثلاثة مساهمات منهجية تتمثل فى :

ا - تحديد واختيار تطبيقات التكافل الصناعي •

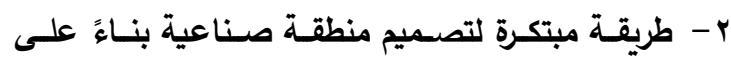
أهداف وقيود مستوحاة من الطبيعة .

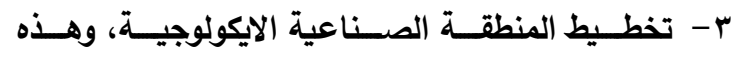
المســاهمات تعتبـر أداة صـــع قـرار هامسة لمصسمي وواضــعي سياســات تصــميم المنــاطق الصـــناعية الايكولوجيـة ، وأهميـة الاراســة فـى تقـــيمها تقنيـة جديـدة لتحقيـق الانتقـال مـن الاقتصـاد الخطى إلـى الخى

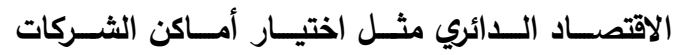
الصــاعية بحيـث تكـون بـالقرب مـن أمساكن إنتـاج النفايات بدلاً من الموارد التقليدية.

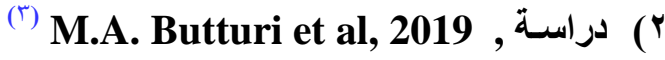
تقــدم هـذه الاراســة اسـتعراض المؤلفــات العلميـة

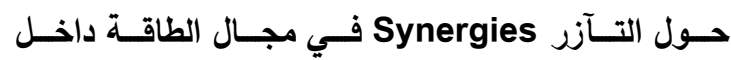

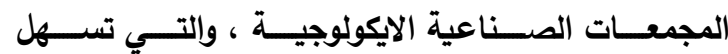

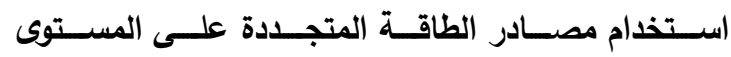

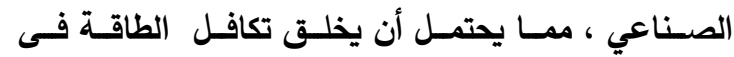

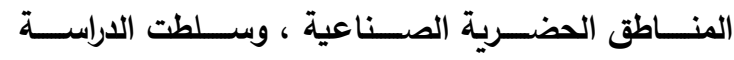
الضـوء علـى أربعسة مســارات رئيسية لتنفيـذ التـآزر في مجـال الطاقـة المتجــدة لوضــع حلـول قابـــة للتطبيـق

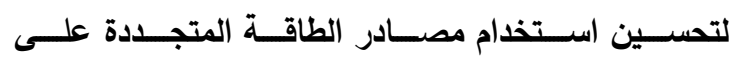
المســتوى الصــناعي والمســارات الاربعــة هــى تبــادل

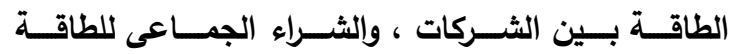
المتجـددة ، وادارة الانتــاج الجمـاعى للطاقـة المتجـددة ، وخدمات المبانى والمرافق المشتركة.

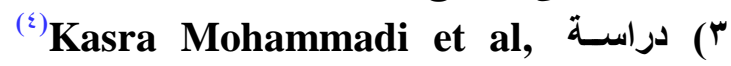
2019 ,

قــدمت هــذه الدراســة مراجعــة لاســتخدام الطاقــة الشمسية الحراريـة فـى تحليـة ميـاه البحر وتوليـ الطاقـة

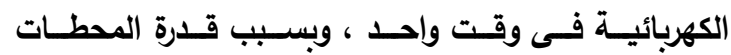
الشمسية الحراربـة فـى انتـاج الكهربــاء وإنتـاج الحـرارة فانــه يمكـن اســتخدام مجموعــة متنوعـة مــن أنظمــة

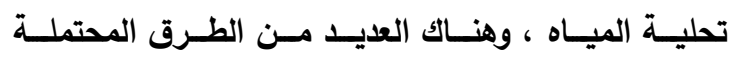

( أهداف البحث

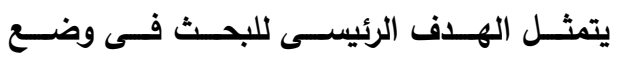

تصـــور فعــال لاســتخدام الطاقـــة الثمســية الحراربــــة

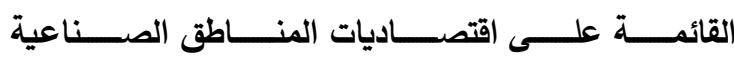
الايكولوجية ، وتحقيق الأهداف الفرعية التالية:

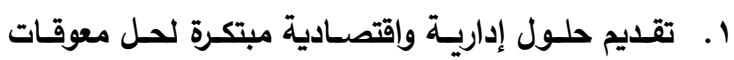
التكاليف العالية لاستخدام الطاقة الثمسية. r. خفــ تكــاليف الإنتــاج وتقـــيم فـرص صــنـاعات

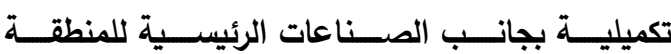
الصناعية الايكولوجية.

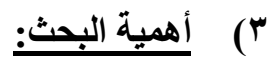

ا. أهميـة نتـائج البحـث لصـانعي ومتخـــي القـرار فـى

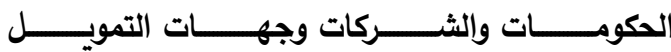
والمستثمرين. r. تقـــيم موضـــوع البحــث كــأداة لتحقيـق التعـــاون الاقتصادي والبيئي بين الثركات الصناعية.

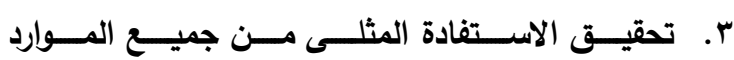
المتجددة وغير المتجددة. ع) المعالجة المنهجية للبحثة:

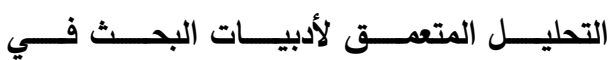

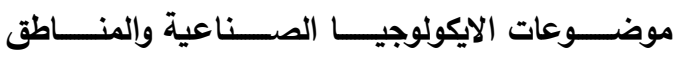

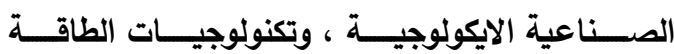
الثمسـية الحراريـة مـع تقــيم تصسور مقترح لتحقيـق التكامسلـل بـين فكــر تصـــيم المنـــاطق الصـــاعية الايكولوجية وتقنيات الطاقة الشمسية الحرارية. 0 ) تقسيم البحث: • المبحث الأول : الإطار العام للبحث.

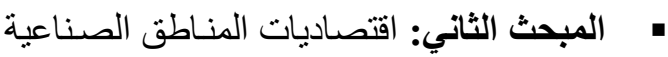
الايكولوجية.

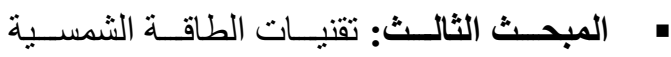
الحرارية وتطبيقاتها في الصناعة

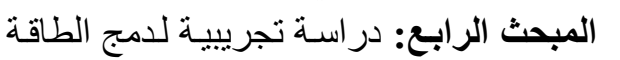
الثمسية الحر ارية مع مخطط لمنطقة صناعية درية

ايكولوجية. - الخلاصة.

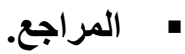
7) الار اسات والحالات التطبيقية السابقة: ( ) مراسـة 2020 (r) Olcay Genc et al 
(') Y) دراسـة, 2015

طبقـت هـذه الدراسـة في جزيـرة Tanegashima اليابانيـة ، حيث هدفت السى إيجـاد تكافل صـناعى فعسال

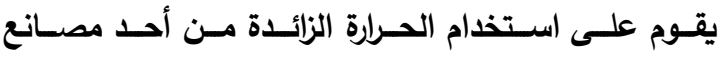

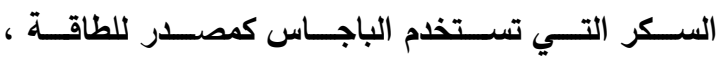

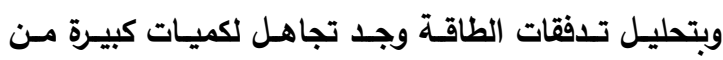

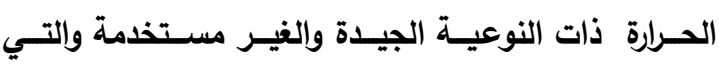
يمكن أن تسـتخدم لســـ الطلب علـى الطاقـة الكهربائيسة

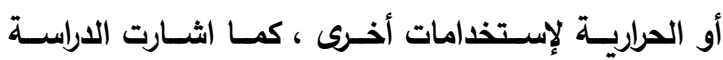

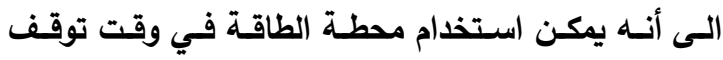

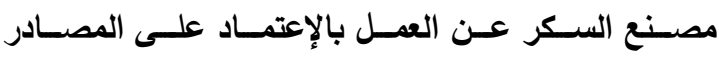

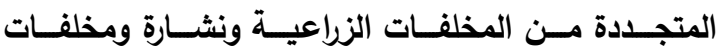
الاخثاب في إنتاج الطاقة لدعم الشبكة المحلية.

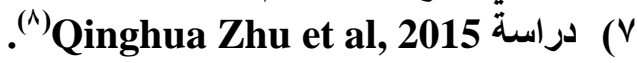

تناولــــت هـــــه الدراســــة المعوقـــــات الداخليـــة

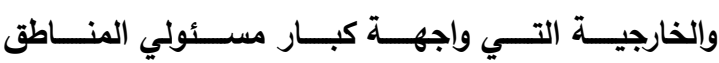

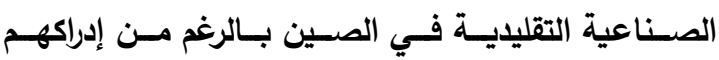

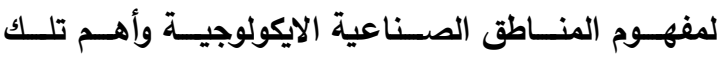

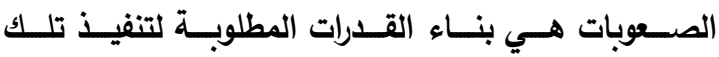
المنـاطق والعراقيـل التكنولوجيـة ، وفـى ظلـ تلـك النتـائج

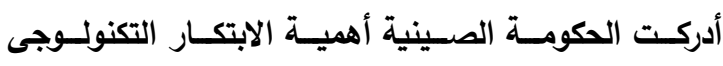

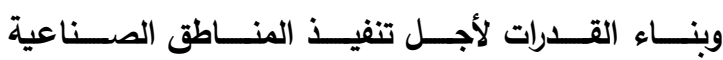

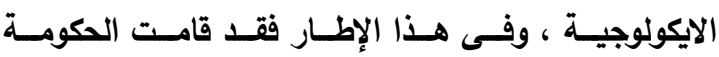

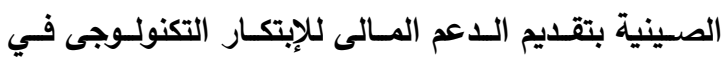

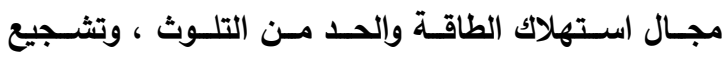
التنمية التكنولوجية والتعاون بين الثركات.

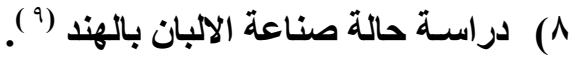

Mahanand تناولــت هـــه الحالــة قيسام شـــــة

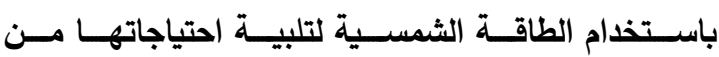

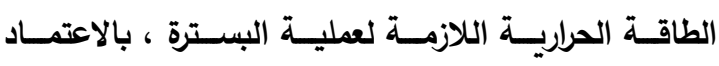
على مرجل شمسي لثـركة ARUN وهسى شـركة يـديرها

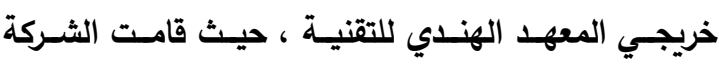

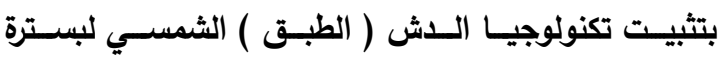

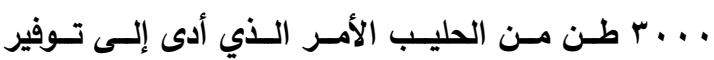

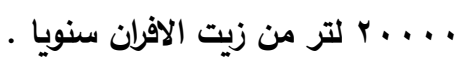

لتهجـين خـــات الطاقـة مـع أنظمـة تحليـة الميـاه مـن

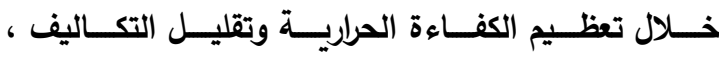
وتـوفير وسـيلة محتملـة لتسـريع تسـويق هـذه المحطـات الهجينة بثكل عام ، وتعتبرمحطات تحلية مياه البحر

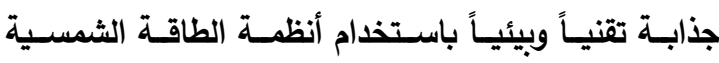

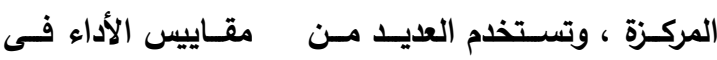

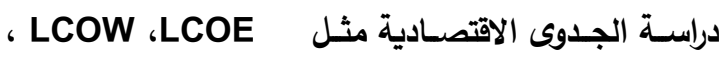

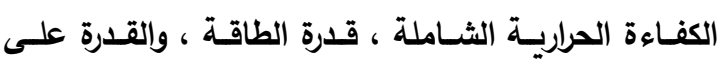
إنتاج المياه العذبة .

ع) (عراسـة , Kody M.Powell et al, 2017

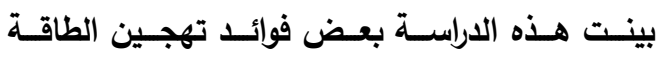

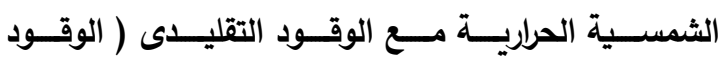

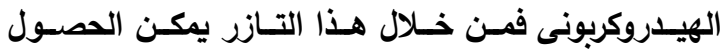

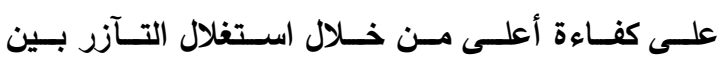

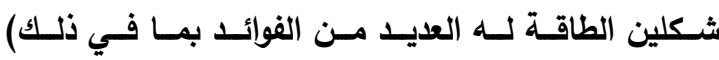

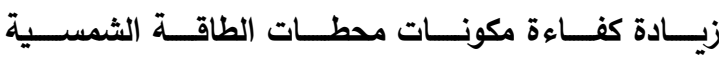

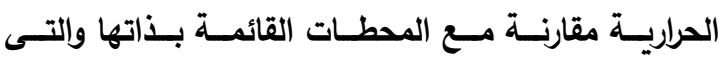

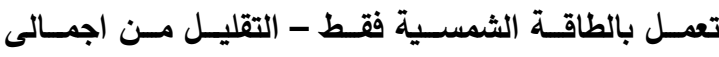

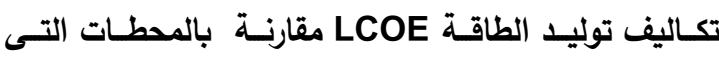

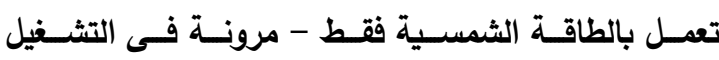

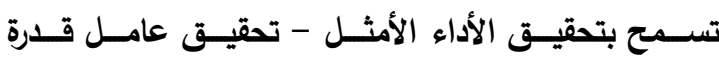
عاليـة - قدرة عاليـة فـى استيعاب حصـة شمسية أكبر

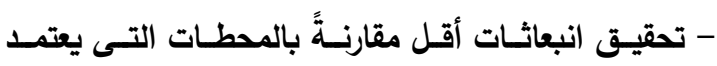
على الوقود الهيدروكربونى فقط .

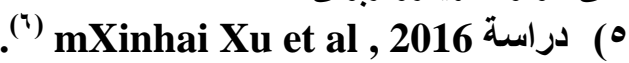

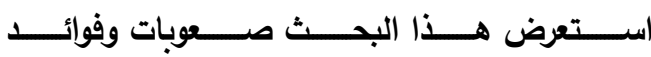

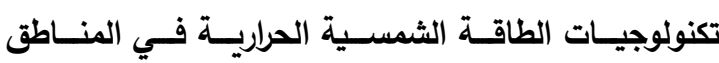

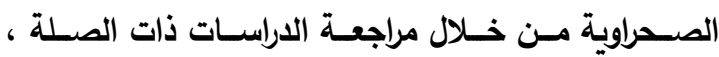

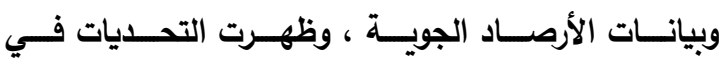

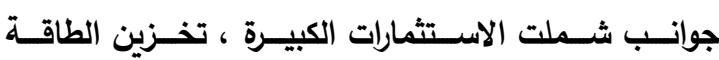

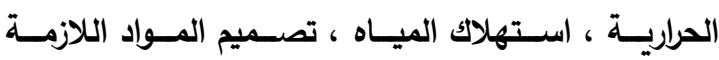

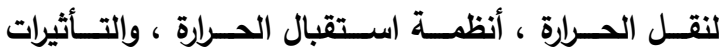

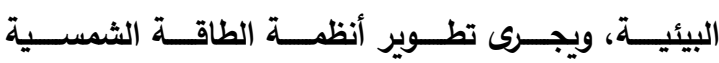

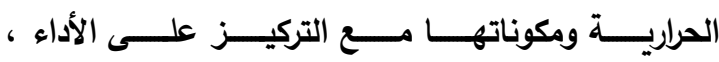

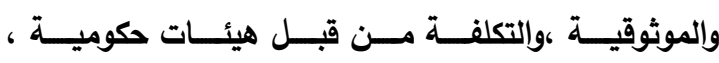
والثركاء في الصناعة. 


\author{
(Bocken ‘Olivetti ،Cullen ،Potting ،\& \\ Lifset ،2017).
}

هـى الطريقــة المدروســة والعقلانيـة التـي تســتخدم

مسن قبـل الثـركات والاقتصــاديات والمجتمعــات للحفــاظ على القـــرة التنافسـية الاقتصـادية والبيئيـة والاجتماعيـة

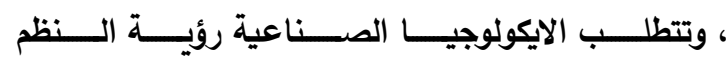
الصـــاعية كجـزئ مــن الســياق الاجتمــاعي والثقــافي والبيئسي لتســاعد فـي تحسـين اسـتهلاك الطاقـة والمـواد علـى مسـتوى العمليـات الصــناعية ومكونــات ومرافـق خطوط الإنتاج( '('). (r ) تعريف المناطق الصناعية الايكولوجية:

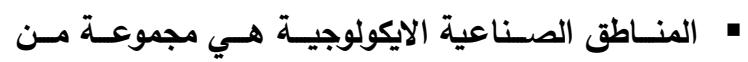
الثـركات الصـناعية والخدميـة التـى تقـع فـى ملكيـة مشـتركة والتـي تسـعى السى الوصسول الـى التحسـين المزودج للتنمية الاقتصادية والبيئية والتعاون في إدارة

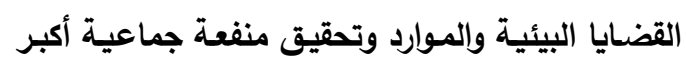
من مجموع الفوائد الفردية لكل شركة (r'). - موذج صناعى جديد يمكنه إيجاد توافق بين الاستدامة وكفاءة الاقتصادية البيئية والاجتماعية ، وتتمثل القوة

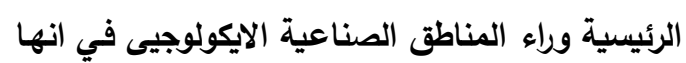

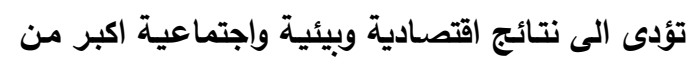
الصناعات التي تعمل بشكل مستقل (rا').

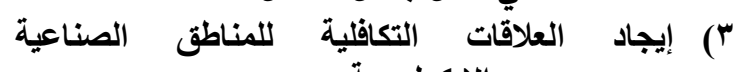
الايكولوجية:

يعرف التكافل الصناعي بأنه نهج جماعي للميزة التنافسية

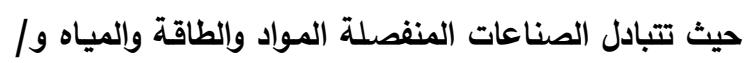
أو المنتجات الثانويـة ، ويؤدى التكافل الصناعي دورًا مهمًا

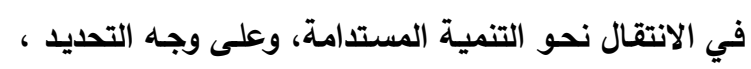

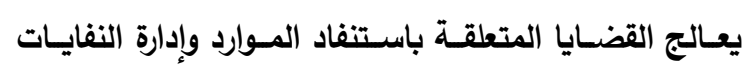
والتلوث باستخدام تدفقات النفايات لتوليد قيمـة أكثر كفاءة عبر شبكات الشركات الصناعية ، ومن أهم أسس التكافل الصناعي هو التعاون المشترك فيما يتعلق بالإمكانيات التي يتيحها القرب الجغرافي (؛ُ). ويوضح الثكل رقم (01) إطار مخصـص لاكتثــاف شـبكات التكافـل الصــناعى بكوريــا الجنوبية(10) - 20.
وكانـت أهـم الصـعوبات التـي واجهـت الثـركة هـي

طــول الفتـرة الزمنيـة التــي تحتاجهــا الطاقـة الثمسـية

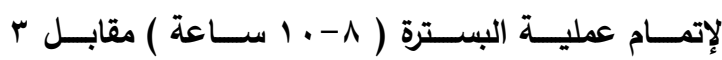

ساعات بالطاقة التقليدية.

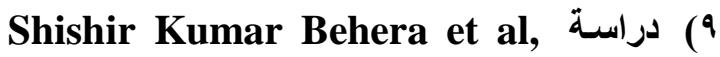

$$
\text { (') } 2012 \text {, }
$$

استنتجت هـذه الاراسـة أن نجـاح شـبكات التكافـل

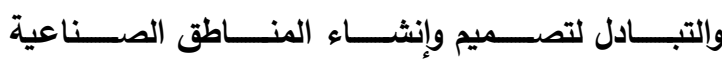

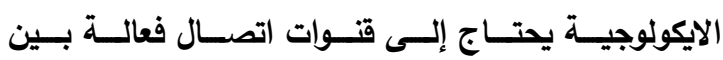

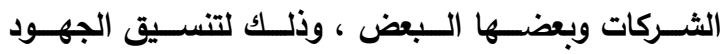
التـي تهـدف إلـى تحويـل المجمعـات الصـناعية التقليديـة

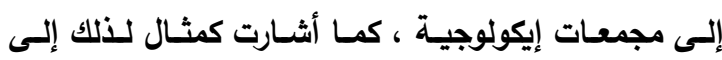

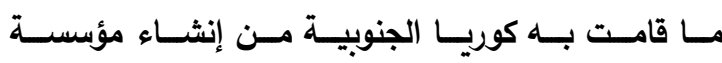

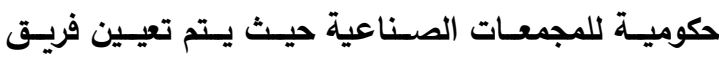

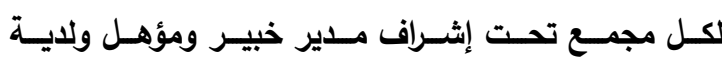
إلمام عميق بثقافة الإيكولوجيا الصناعية. المبحث الثانى: اقتصاديات المناطق الإكوياتئية الصناعية. الايكولوجية ( )

تثـــمل الإيكولوجيــا الصــناعية مجموعــة واســعة

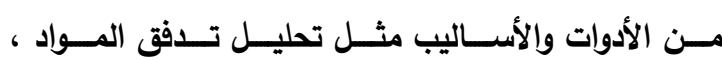

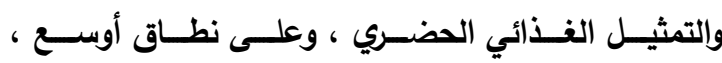

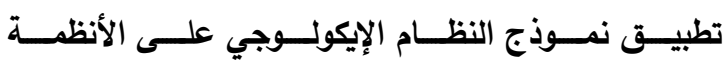
الصــاعية (علـى سـبيل المثــال ، التعـايش الصــناعي) ينبثـق بثـكل طبيعـي مـن منظــور البيئسة الصـــاعية.

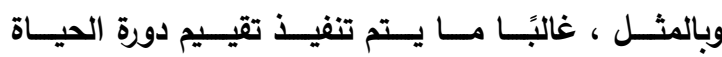

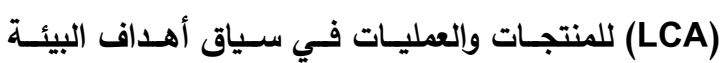

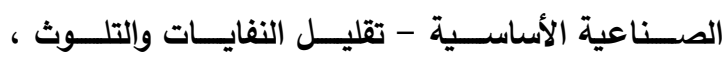
وتعظيم الكفـاءة ، وتعزيـز التـفقات الدوريسة. في الآونـة الأخيـرة ، تـم تطوير المفهـوم الناشــئ للاقتصـاد الــائري

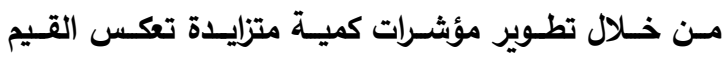

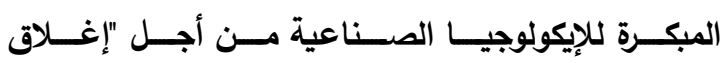

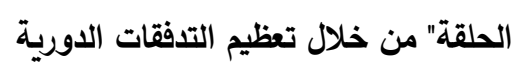


شكل رقم (1 + ): إطار مخصص لاكتثاف شبكات التكافل الصناعى بكوريا الجنوبية (1')

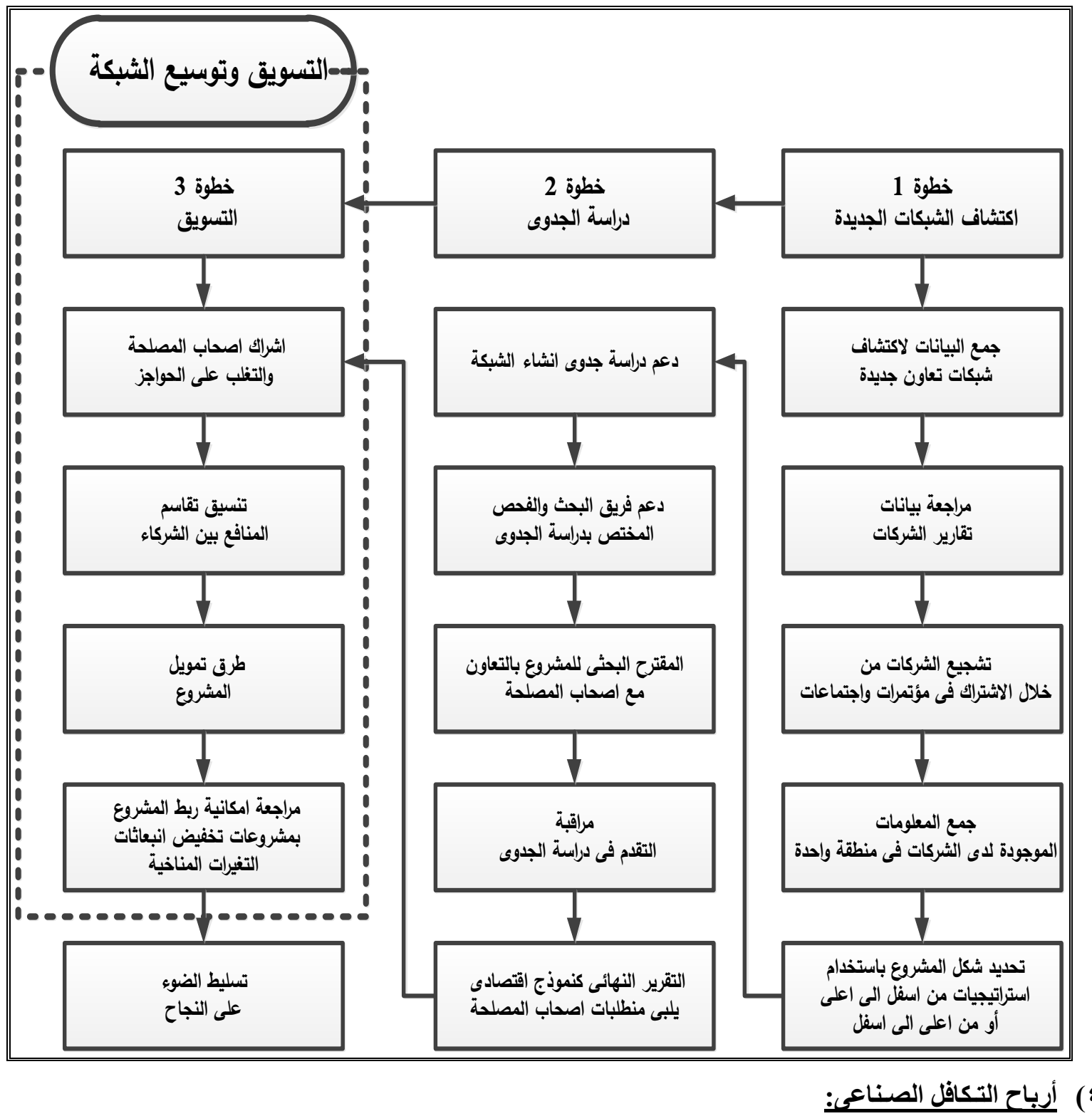

حيــــث لا يكــــــ....m)

هنــاك تكافـل صــناعى، ويعكس ربــح التكافـل جـوهر

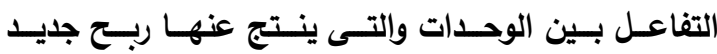

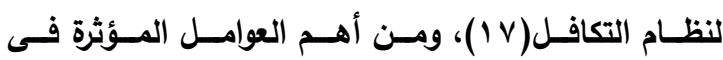

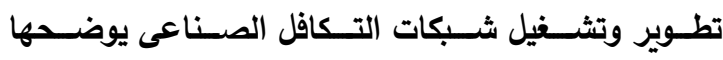

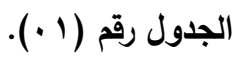

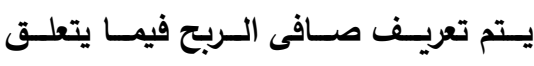
بعملية التكافل كما فى المعادلة التالية: $E=\sum_{i=1}^{m} E_{i}+\operatorname{Es}$

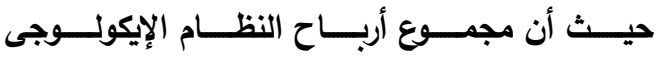

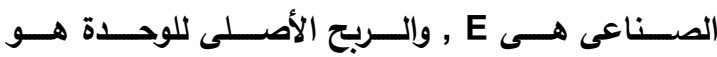




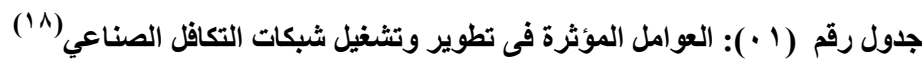

\begin{tabular}{|c|c|c|}
\hline المجالات المحتملة للتأثير & خصائصه & العوامل \\
\hline ـ ـ ـ حجم المكاسب الاجتماعية والاقتصادية والبيئية. & 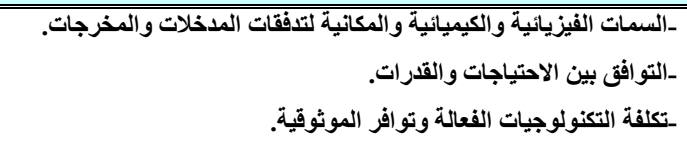 & الفنية \\
\hline ـ ـ الحاجة اللى بتفادة الاقتصادية والقدرة التنافسية المكتسبة. & ـ ـ ـ ـ تكاليفة النفايات والمواد الأولية. & الاقتصادادة \\
\hline ـ ـ ـ الابتكار والتنمية المباثرة. & ـ ـ ـ العياسات البيئية الثاملة. & السياسية \\
\hline ـ ـ قدرات محتملة لتفعيل التعاون والتَّآزر. & 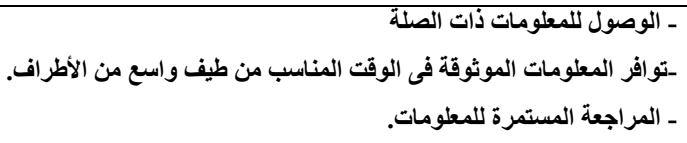 & المطلوماتية \\
\hline
\end{tabular}

الثانويـة ، مـع دعم التحسين فى الأداء البيئسى بثكل

فردى والمنطقة بثكل جماعى.

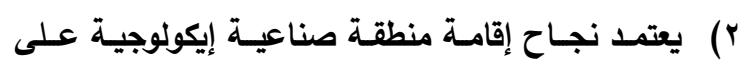
(القدرة على الابتكار - الوصول إلى الأسواق - القدرة

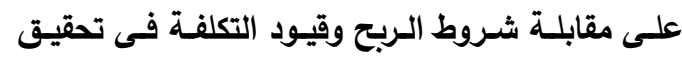

تعاون بين مختلف الثركات والمنثآت الصناعية ).

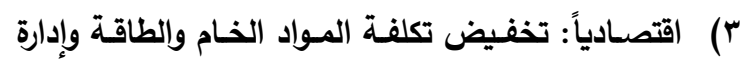

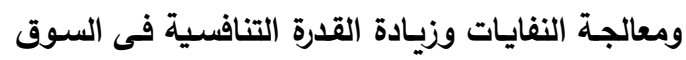

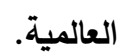

؛) بيئيا: الحد من الطلب على المـوارد المحدودة وجعل

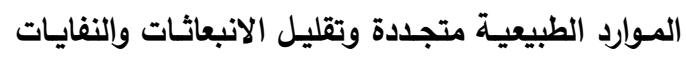

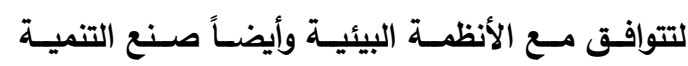

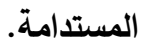

ه) اجتماعيا: خلق فرص عمل جديدة، وتطوير فرص

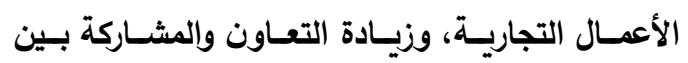
محتلف الصناعات.

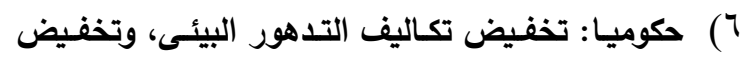

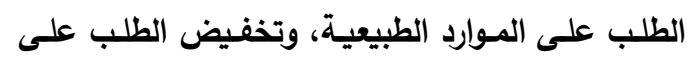

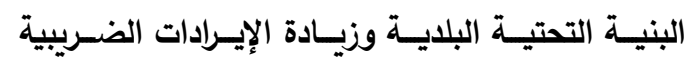

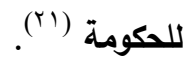

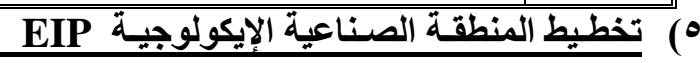

\section{Eco-Industrial Park}

يقتـرح Ayres أن النظــام الإيكولـوجى الصــاعى

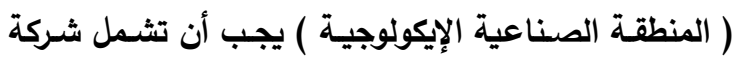

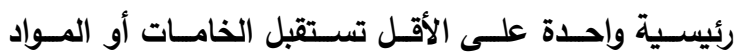

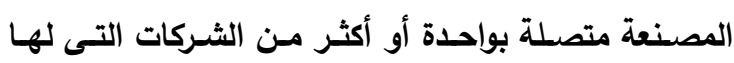

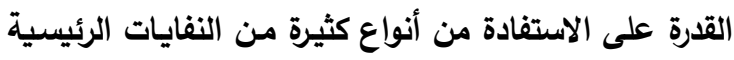
التى من شأنها تحويل العديد من النفايات إلى منتجات قابلة

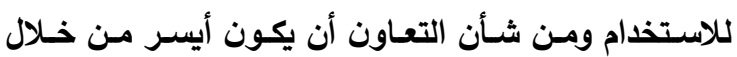

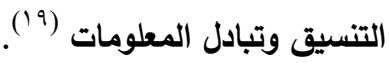
فو ائد المنطقة الصناعية الإيكولوجية (م) (r)

( ) إنشاء أعمال تجارية محلية جديدة مع توسع المنشآت القائمة.

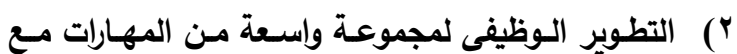
مجموعة واسعة من الأجور.

٪) استخدام المواد الثانوية والنفايات والطاقة المفقودة.

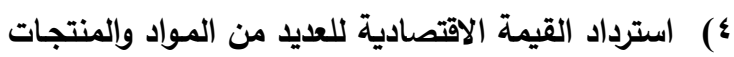

$$
\text { التى تلقى فى مقالب النفايات. }
$$

ه) الاستفادة من الفاقد فى المنتجات الزراعية والغذائية. الإدارة الفعالة للمنطقة الصناعية الإيكولوجية: الزية الفئية

() ) الحفاظ على مزيج من الثركات المطلوبة لتكوين أفضل اسـتذام متبـادل بين بعضهم البعض مسن المنتجـات 
(r) منطقة Crewe Business Park بمدينة تثيشير

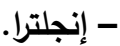

ع ) منطقة Environment Park in Turin - إيطاليا .

(0) منطقة -Vreten Park in Stockholm السويد.
7) نقاط القوة لبعض المنـاطق الصناعية الايكولوجية

\section{الأخرى طبقا للجدول رقم (r •):}

Kalundborg المنطقة الصناعية الايكولوجية مدينة

بالانمارك.

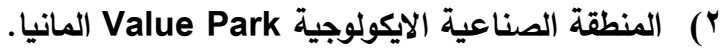

جدول رقم ( r · ) : تحليل نقاط القوة وانجازات بعض المناطق الصناعية الايكولوجية (r)

\begin{tabular}{|c|c|c|c|c|c|c|}
\hline \multicolumn{5}{|c|}{ تحليل خمسة مميزات المناطق الضناعية الايكولوجية } & \multirow[t]{2}{*}{ نقاط القوة } & \multirow[t]{2}{*}{ الحالة } \\
\hline الإجبراءوات & الطينيجة & المشتدانمة & المواردة & التالعناديرة & & \\
\hline \multirow[t]{4}{*}{$\sqrt{ }$} & & & $\sqrt{ }$ & $\sqrt{ }$ & 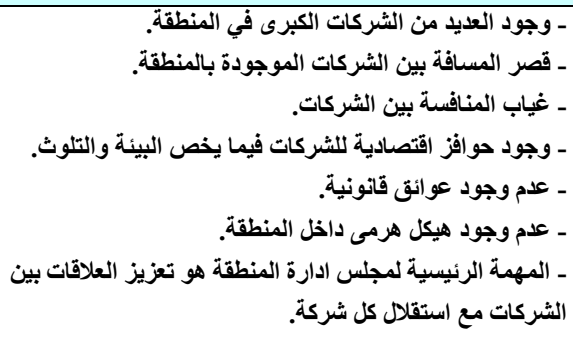 & (1) \\
\hline & & & $\sqrt{ }$ & $\sqrt{ }$ & 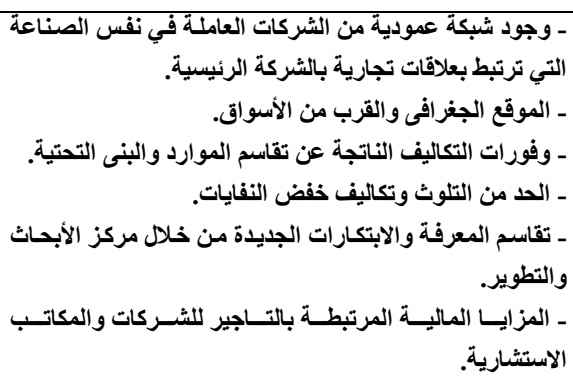 & $(r)$ \\
\hline & $\sqrt{ }$ & & & & 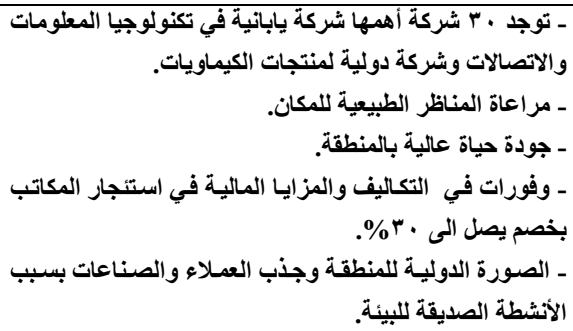 & $(\Gamma)$ \\
\hline & & & $\sqrt{ }$ & $\sqrt{ }$ & 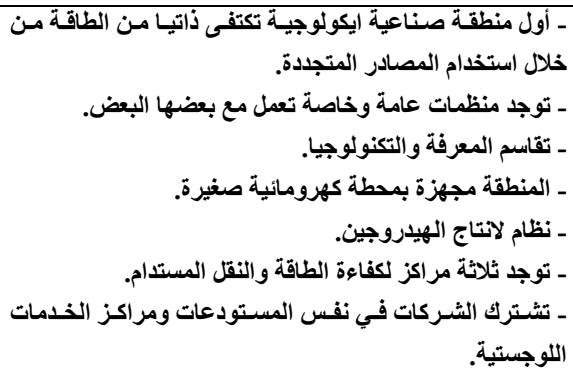 & $(\xi)$ \\
\hline$\sqrt{ }$ & & $\sqrt{ }$ & $\sqrt{ }$ & $\sqrt{ }$ & 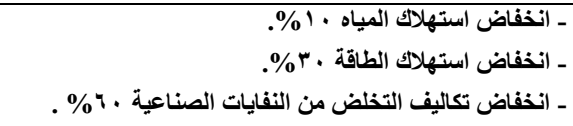 & $(0)$ \\
\hline
\end{tabular}


وتتوفر الطاقة الثمسية مباشرة من الطاقة التي تنتجها

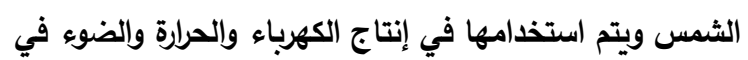
أنظمة الطاقة الثمسية ، وتستمد الثمس طاقتها من الاندماج النووي عن طريق تحويل ملايين الأطنان من الهيدرجين إلى طئل

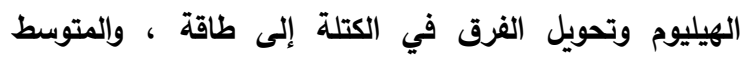

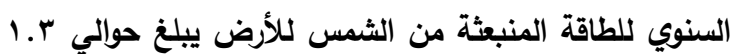

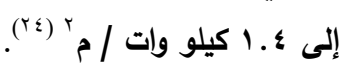

التكنولوجيا ذات القطع المكافئ الاسطوانى

\section{Parabolic Trough System}

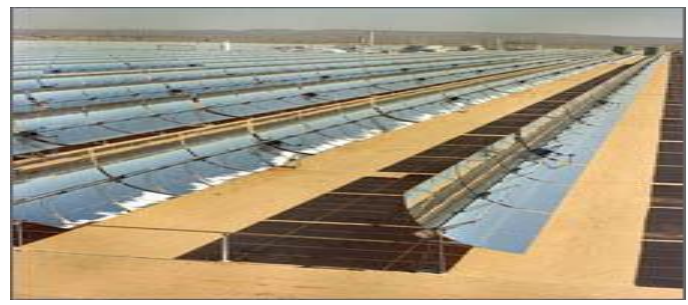

\section{الوصف}

هو النظام الأكثر شيوعاً على المستوى التجارى، يتم فى التى هذا النظام وضع أنبوب المتلقى Receiver على الخط النط البؤرى من كل عاكس على شكل قطع مكافىء حيث يتم تسخين السائل الناقل للحرارة ليقوم بتحويل الماء إلى فئل بخار لتوليد الكهرباء (ro).
المبحث الثالث

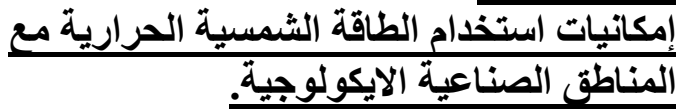

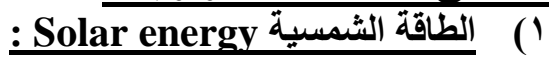

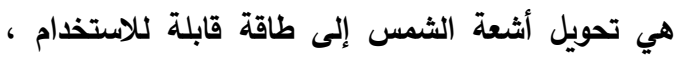
وهى طاقة طبيعية غير مستقرة سواء داخل اليوم (الليل والنهار والغيوم) وخلال السنة (الثتاء والصيف)، ويعتبر تخزين الطاقة الثمسية أمر بالغ الاهمية إذا ما كان سيتم الاعتماد على الثمس في انتاج الطاقة الكهربائية والحرارية (بr) C أهم تقنيات الطاقة الثمسية الحرارية أو المركزة:

تكنولوجيا الأبراج الثمسية

\section{Solar Power Tower}

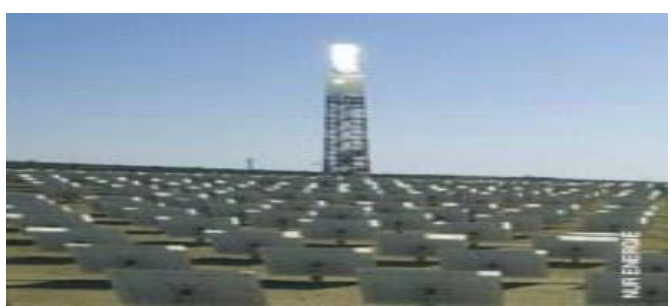

الوصف

تستخدم هذه التكنولوجيا برج الطاقة ويقع تحت البرج العديد من المرايا المسطحة التى تقوم بتتبع الثمس لتهن

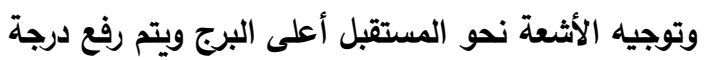
حرارة السائل الأى يستخلم فى توليد البخار لتثغيل التوربينات التى تستخدم فى تشغيل المولدات، وتستحدم هذه الأبراج نوع من أنواع تخزين الحرارة لتوليد الكهرباء

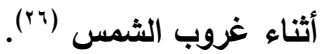


؛) استخدام الحرارة والحرارة المفقودة لصناعات

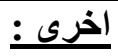

يمكن للطاقة الشمسية الحرارية توفير قدر كبير من الطلب على الحرارة في العمليات الصناعية الغذائية

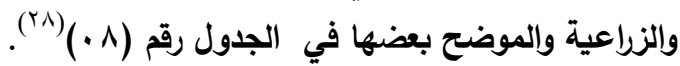

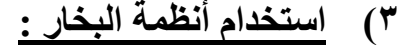
تمثل أنظمة البخار حوالى ·r\% من الوقود الاحفورى

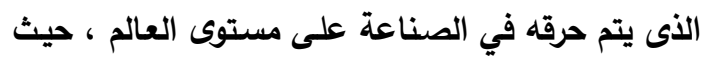

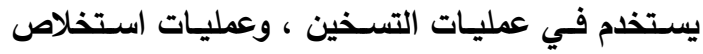

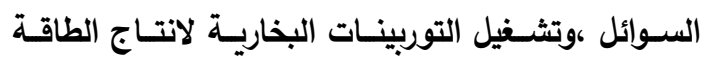
الكهربائية ويوضـح الجدول رقم (v •) تقديرات استخدام البخار في الصناعات المختلفة (TV')

جلول رقم (ף • ): تقديرات استخدام البخار في الصناعات المختلفة

\begin{tabular}{|c|c|}
\hline نسبة البخار من الطاقة المستخدمة في القطاع الصناعى & القطاع الصناعى \\
\hline$\%$ \% & صناعة الورق ومنتجاته \\
\hline$\%$ \%r.q & صناعة المنتجات الكيميائية \\
\hline$\%$ \%Y.r & المنتجات البترولية والفحم \\
\hline$\% 11.9$ & تكرير البترول \\
\hline$\% 11.1$ & الصناعات الغذائية \\
\hline$\%$ \% .9 & المنتجات الخشبية \\
\hline$\%$ \%.। & صناعة التعلين \\
\hline$\%$ \%.० & منتجات الصلب \\
\hline$\%$ \%५.r & صناعة النسيج \\
\hline$\%)^{\prime} . r$ & البلاستيك والمطاط \\
\hline
\end{tabular}

جدول رقم (v •):العمليات الصناعية ودرجات الحرارة المطلوبة من الطاقة الثمسية المركزة

\begin{tabular}{|c|c|c|}
\hline مدى درجة الحرارة Co & العملية الصناعية & القطاع الصناعى \\
\hline q.-r. & Drying التجفيف & \\
\hline $9 .-4$. & الغسيل Washing & \\
\hline$\Lambda \cdot-r$ & Pasteurising البسترة & |لصناعات الذذابنة \\
\hline 1.0 .90 & Boiling الغليان & الصساعت العدالية \\
\hline $1 r \cdot-11$. & Sterilising التعفيم & \\
\hline $7 \cdot-\varepsilon$ & Heat Treatment المعالجة الحرارية & \\
\hline$\lambda \cdot-4$ & Cooking and Drying الطبخ والتجفيف & \\
\hline $9 .-4$. & Boiler feed water تغذية الغليات & صناعة الورق \\
\hline $10 \cdot-14$. & Bleaching التبييض & \\
\hline $1 \cdots+1$ & التبييض Bleaching & \\
\hline q.-v. & Dyeing التجفيف & صناعة المنسوحات \\
\hline $1+\cdot-1 \ldots$ & Drying, De-greasing التجفيف وإزالة الثحوم & \\
\hline$\Lambda \cdot-\varepsilon \cdot$ & Washing الغسيل & \\
\hline
\end{tabular}

الدورة التي تعمل بالفحم أو المواد البترولية (ج9). ويؤدى هذا الأسلوب الى تقليل التكاليف بثكل كبير وتجنب تكاليف بعض البنود مثل تكاليف تذزين الحرارة من ناحية وزيادة الحقل الثمسى وأنظمة التخزين نفسها.
0) تهجـين الطاقـة الثمسـية الحراريـة مـع الوقـود الاحفورى الطين هناك العديد من التحسينات الاقتصادية فى التكاليف والأداء وتقليل مخاطر المشروع لتهجين الطاقة الثمسية الثانية

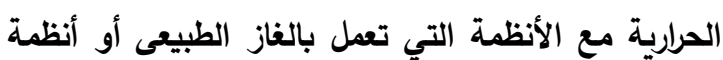


اللقيطة بالصحراء الثرقية. ويوضـح الشكل رقم (^ • ) مقترح تخطيط منطقة صناعية ايكولوجية من تحليل تدفقات المواد والطاقة للصناعات الموجودة بالمنطقة بالإضافة الى الموارد الطبيعية المتوافرة. شكل (08) شبكة التكافل الصناعى ( المنطقة الصناعية الإيكولوجية)

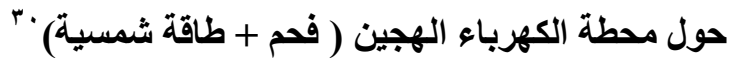

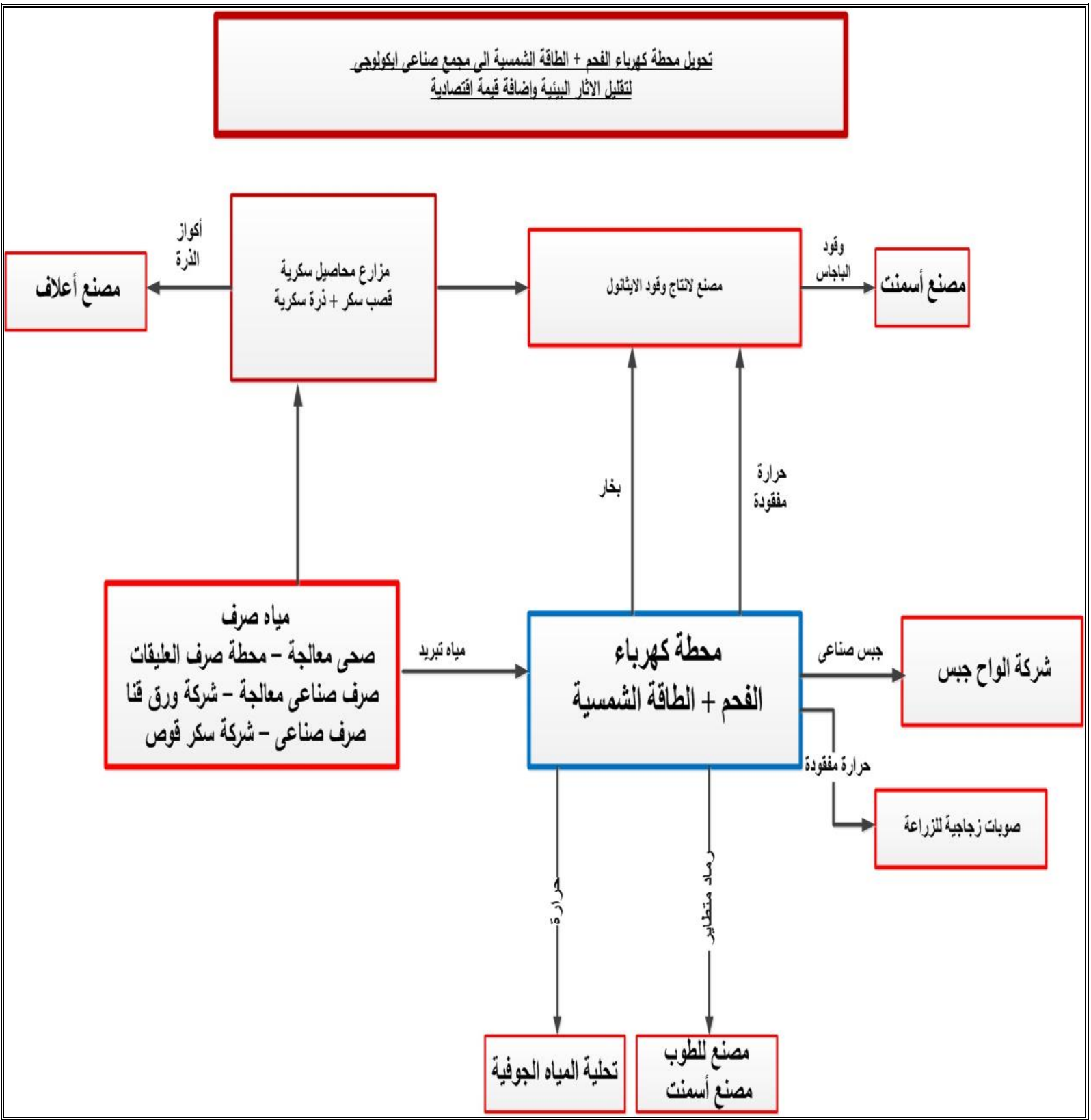

العربية ، وتم الحصول على على المعلومات من شركة IA TECH
لدراسـة تجريبية لـمتج الطاقـة الثمسية الحراريـة

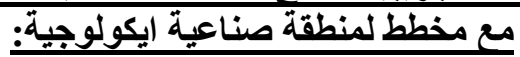

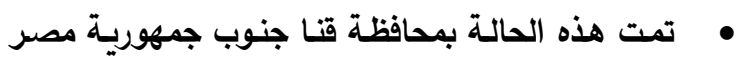
العربيـة ، حيث تم دراسـة إمكانيـات إيجـاد شبكة مـن فئن

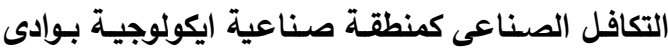

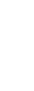


جدول رقم (1 • ): تقديرات الطاقة الشمسية الحرارية مع الفحم الحجرى

\begin{tabular}{|c|c|c|}
\hline 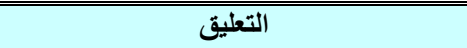 & 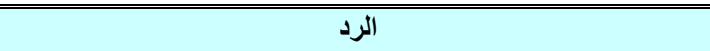 & السؤال \\
\hline يمكن خفض تلك التكاليف بذخول مقاولين ومكونات محلية & Total CAPEX is about $2,800,000,000 €$ for $2,100 \mathrm{MWnet}$ electric & $\begin{array}{l}\text { An estimation of the } \\
\text { total cost of coal - solar } \\
\text { project } 2000 \text { MW. } \\
\text { تقيرير التكاليف الاولية }\end{array}$ \\
\hline بلا باءة عالية تصل الى $40 \%$ & $\begin{array}{l}\text { Hybridization is THE approach to convert fossil fuel power } \\
\text { economy to a sustainable affordable and environmental friendly } \\
\text { one. Efficiency of hybridization would be high, because large scale } \\
\text { coal power plants benefit from high efficiencies in the power block } \\
\text { of more than } 40 \%+- \text { when injecting solar produced steam in the } \\
\text { life-steam path of the coal fired facility, the solar steam is then } \\
\text { converted at high efficiency, e. g. } 40 \% \text { depending on the cooling. } \\
\text { However solar field too close to the coal fired power plant would } \\
\text { suffer from the blocking of the water steam clouds coming out of } \\
\text { the cooling towers- best would be to cool with Nile-water. }\end{array}$ & $\begin{array}{c}\text { The efficiency of } \\
\text { hybridization } \\
\text { كفاءة التهجين - فحم + أشعة شمسية }\end{array}$ \\
\hline 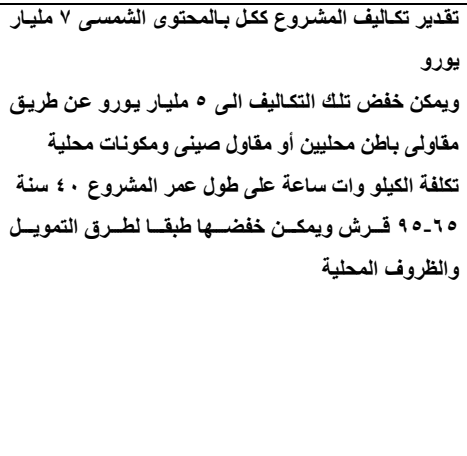 & $\begin{array}{l}\text { Total Project volume for the solar tower would be approx. } \\
4,200,000,000 € \text { for the solar steam production (to produce solar } \\
\text { steam at } 700 \text { MWel equivalent-share for the power block of the } \\
\text { coal plant at max. capacity of } 2,100 \text { MWnet) }+2,800,000,000 € \text { for } \\
\text { the coal plant (making at peak } 2,1 \mathrm{GW} \text { when some days are } \\
\text { without solar) }=\mathbf{7 , 0 0 0 , 0 0 0 , 0 0 0} \\
\text { GWh } \\
\text { Generating approx. } \S \text { Total annual electric energy: } 15,400,000 \\
\text { \$ Levelized Cost of Electricity: } 65-90 € / M W h e l \text { (Depending on } \\
\text { financing, coal price and carbon credits) } \\
\S \text { Emission: } \quad 580-650 \text { t_CO2/MWh,el }\end{array}$ & $\begin{array}{c}\text { Your opinion about the } \\
\text { ratio of } 65 \% \text { coal and } \\
35 \% \text { of solar. } \\
\text { تكاليف المحتوى الشمسى ثم كلى }\end{array}$ \\
\hline 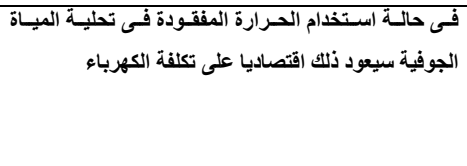 & $\begin{array}{l}\text { For the water desalination this fully depends on the local } \\
\text { conditions, but would be commercially beneficial for the project, so } \\
\text { levelized cost of electricity could be decreased additionally } \\
\text { significantly. }\end{array}$ & $\begin{array}{l}\text { The positive effect of the } \\
\text { project from the side of } \\
\text { water desalination }\end{array}$ \\
\hline
\end{tabular}

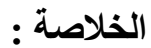

ثبــت مــن هــا البحــث انــهـ يمكـن تخفــيض

تكـاليف اسـتخدام الطاقـة الثمسية الحراربـة بثـكل كبيـر عـن طريــق اســتخدمها ضـــمن المنـــاطق الصـــناعية

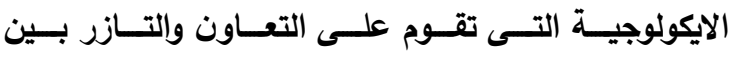

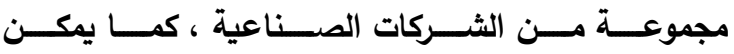
للحكومــات أن تكــون شــربك فــى المنــاطق الصــناعية الايكولوجيـة وتقـــيم الحــوافز اللازمــة لنجــاح اسـتخدام الطاقة الشمسية الحرارية ومن أهم النتائج الاخرى: () يمكـن اســتخدام المنــاطق الصــناعية الايكولوجيـة كأسلوب لخفض تكاليف الصناعة.

r ) دمـج المنـاطق الصــاعية الايكولوجيـة مـع اسـتخدام الطاقـة الشمسـة يـــعم القـــرة التنافسـية للصــاعات

المتجاورة.
يمكن اقامة عدة صناعات مثل صناعة الأسمنت التى يمكن ان تعتمـد على الفحم بطريقة نقل امنـة وايضـا صـناعة الاســمدة والسـيراميك والرخـام وغيرهـا مـن المعادن الموجودة بالمنطقة. تظراً لتوافر الطاقة الكهربائية بمنطقـة المشروع فأنـه يمكن نقل الألمونيوم الخـام مـن مصنـع نجـع حمـادى وإقامة عدد كبير من المشروعات الصناعية للتصدير والاستخدام المحلى مثل ( صناعات الطاقة الثمسية ، صناعة قطع غيار السيارات ، الأسلاك والكابلات. يمكن استخدام الحرارة الأقل من · ^ درجة مئويـة فحى تحلية المياه الجوفية .

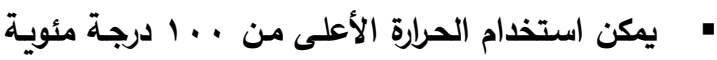
فـى إنتـاج البخـار المسـتخدم فـى بعـض التطبيقـات الصناعية مثل صناعة الايثانول. " التخلص من الرماد الناتج عن حرق الفحم في صناعة الطوب. 


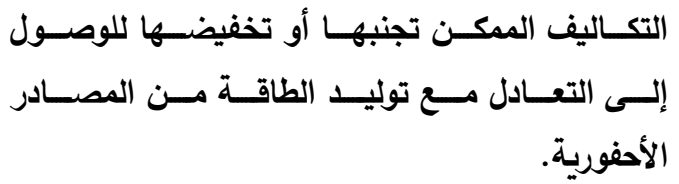

\section{REFERENCES:}

(1) Ren Ling-zhi: Cost-benefit evolution for concentrated solar power in China, Journal of Cleaner Production, Volume 190, 20 July 2018, Pages 471.

(2) Olcay Genc et al: Circular eco-industrial park design inspired by nature: An integrated non-linear optimization, location, and food web analysis, Journal of Environmental ManagementVolume 270, 15, 2020.

(3)M.A. Butturi et al,. Renewable energy in eco-industrial parks and urbanindustrial symbiosis: A literature review and a conceptual synthesis, Applied Energy, 255, 2019.

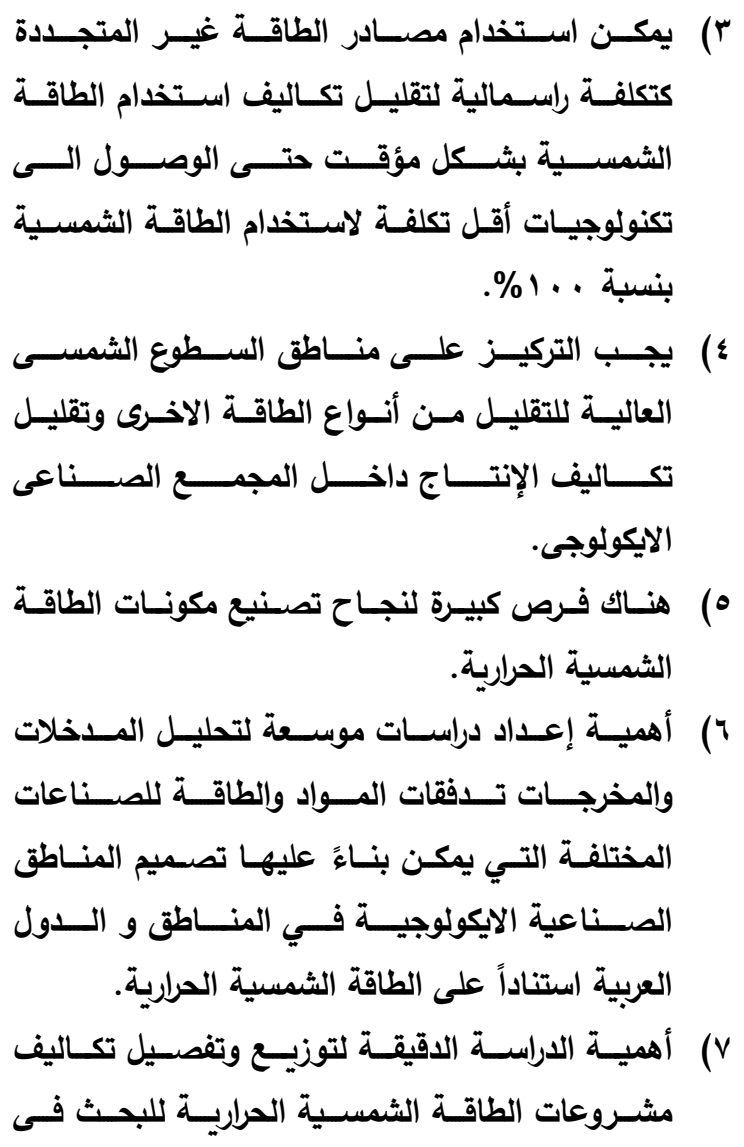

(4) Kasra Mohammadi et al: Hybrid concentrated solar power (CSP)desalination systems: A review, Desalination ,Volume 468, 2019.

(5)Kody M.Powell: Hybrid concentrated solar thermal power systems: A review, Renewable and Sustainable Energy Reviews Volume 80, 2017.

(6)Xinhai Xu et al: Prospects and problems of concentrating solar power technologies for power generation in the desert regions, Renewable and Sustainable Energy Reviews, Volume 53, January 2016, Pages 1106-1131. 
(7)Yasunori Kikuchi et al, Industrial Symbiosis Centered on a Regional Cogeneration Power Plant Utilizing Available Local Resources A Case Study of Tanegashima, Journal of Industrial Ecology, Volume 20, Number 2,2015.

(8)Barriers to Promoting Eco-Industrial Parks Development in China Perspectives from Senior Officials at National Industrial Parks, Journal of Industrial Ecologym Volume 19, Issue 3, pages 457-467, 2015.

(9)http://www.cliquesolar.com/DairyIndustr y.aspx

(10)Shishir Kumar Behera et al: Evolution of 'designed' industrial symbiosis networks in the Ulsan Eco-industrial Park: 'research and development into business' as the enabling framework, Journal of Cleaner Production, 29-30 ,(2012).

(11) T.E Gradel \& B.R Allenby: Industrial Ecology and sustainable Engineering, published by pearson Education,Inc,USA.2010,P32.

(12) world Bank Group: An International Framework For Eco-Industrial Parks, https://openknowledge.worldbank.org/ bitstream/handle/10986/29110/122179WP-PUBLIC-

AnInternationalFrameworkforEcoIndu $\underline{\text { strialParks.pdf?sequence=1\&isAllowed }}$ $=\mathrm{y}$, 2017, P21
(13)Pei Zhong, Weili Xia \& Bing Xu: Study on energy efficiency model in Xi'an Hightech eco-industrial park, Published in 2010 Asia-Pacific Power and Energy Engineering Conference,P1.

(14) Brian Baldassarre: Industrial Symbiosis: towards a design process for eco-industrial clusters by integrating Circular Economy and Industrial Ecology perspectives, Journal of Cleaner Production,Volume 216, 2019, Pages 446-447.

(15) Shishir Kumar Behera et al: Evolution of 'designed' industrial symbiosis networks in the Ulsan Eco-industrial Park: 'research and development into business' as the enabling framework, Journal of Cleaner Production, 29-30 ,(2012), P107.

(16) Shishir Kumar Behera et al:, P107.

(17) Gang Wang: novel approach for stability analysis of industrial symbiosis systems, Journal of Cleaner Production, Volume 39, January 2013, Pages 9.

(18) Murat Mirata: Industrial Symbiosis A tool for more sustainable regions?, Doctoral dissertation, Lund University, Sweden, 2005, P48.

(19) Raymond P. Co^te' \& E. CohenRosenthal: Designing eco-industrial parks: a synthesis of some experiences, Journal of Cleaner Production , 6 , 1998 P 182. 
(20) Raymond P. Co^te' \& E. CohenRosenthal: P 182.

(21) Salah M. El-Haggar: Sustainable Industrial Design and Waste Management Cradle-to-cradle for Sustainable Development, The American University of Cairo, Elsevier Academic Press,2007,P92.

(22) Alfredo Valentino: Eco-industrial parks: the international state of art, Eco-Industrial Parks: A Green and Place Marketing Approach, Luiss University Press,2015, from P24P41.

(23) H.L. Zhang et al: Concentrated solar power plants: Review and design methodology, Renewable and Sustainable Energy Reviews 22(2013),P467.

(24) Mukhtar Ahmad: Operation and Control of Renewable Energy Systems, chapter 5, John Wiley \& Sons, Ltd, 2017,P95

(25)http://www.eere.energy.gov/basics/rene wable energy/linear concentrator.html
(26)http://en.wikipedia.org/wiki/PS20_solar _power_plant

(27)Dan Einstein: Steam Systems in Industry: Energy Use and Energy Efficiency Improvement Potentials,aceee.org/files/proceedings/... /SS01_Panel1_Paper46.pd,P538.

(28)IRENA : Solar Heat for Industrial Processes -Technology Brief, www.irena.org, January 2015, P15

(29)Sargent \& Lundy LLC Consulting Group Chicago, Illinois: Assessment of Parabolic Trough and Power Tower Solar Technology Cost and Performance Forecasts, www.nrel.gov/docs/fy04osti/34440.pd,2 003,P2-5

الباحث (")

(31) Dipl. Eng Johannes Schrufer - Spin-off Company IA TECH from the SolarInstitute Juelich of Aachen University of Applied Sciences - Germany. 


\title{
USING ECO- INDUSTRIAL PARK IN REDUCING THE COSTS OF CONCENTRATING SOLAR POWER
}

\author{
Mahmoud Sayed Ali Alsadk
}

PhD in Industrial Ecology, Ain Shams University, Representative of Egypt in the African Circular Economy Network ACEN, PA-CEMP Certified Expert in Energy Management, Certified Expert in Environmental Economics and Environmental Accounting, mahmoud_sayed101074@yahoo.com

\begin{abstract}
:
This research aims to reduce investment costs of Solar thermal energy Applications such as steam, heat and electricity within eco-industrial park as an example of industrial symbiosis development to reduce resource consumption and waste or pollution generation in eco-industrial park.

This research sets up a model of synergistic effect based on Solar thermal energy Applications and exchange materials and energies in the park between industries in Qena governorate.

The results show that the costs of using solar thermal energy can be significantly reduced by using it within the eco-industrial park based on synergies between a group of industrial companies, and government could play a critical role to drive this concept for success by providing the necessary incentives, such as free cost land. It also showed that fossil fuels can be used as capital costs to reduce solar energy costs.
\end{abstract}


Ass. Univ. Bull. Environ. Res. Vol. 23 No. 2 October 2020 
Ass. Univ. Bull. Environ. Res. Vol. 23 No. 2 October 2020 